\title{
Influences of Hospitals Structure on Medical Malpractice Claim Costs
}

\author{
Article by Ifeanyi Gregory Mbakwe \\ B. Sc. (Microbiology) Texila American University, Nigeria \\ Email: gregmbakwe@hotmail.com
}

\section{Source}

Young, C. C. \& Williams D. R. "Influences of Hospitals Structure on Medical Malpractice Claim Costs, “Academy of Health Care Management Journal, 2011, Vol 7, No. 1, Pp. 1 - 14, viewed on the December 15, 2014,

http://www.alliedacademies.org/Publications/Download.aspx?fid=562

\section{Introduction:}

This article review critically appraises the article 'Influences of Hospitals Structure on Malpractice Claim Costs' in the Academy of Health Care Management Journal. The article was written by Young, C.C. and Williams, D. R. of the Mississippi State University and Appalachian State University respectively in Florida, United States of America, USA. No background information was given about the authors of this article as to their position or discipline in their respective universities. This study which was conducted in the State of Florida, USA, sought to examine the structural factors affecting the total amount of malpractice claims costs by hospitals. The article was published online in portable document format (pdf) and used in-text references throughout the article in a way that unraveled the authors thought pattern which flowed seamlessly and brought about a clear view of the topic under discuss: what they hoped to achieve and how to go about it in a way that made reading interesting. This review will first summarize the article. Secondly, it will briefly analyze the effectiveness of the article's structure, investigating how the information is set out, vocabulary and how easily the reader can access it. Thirdly, the review will critique the article, evaluating its authority, currency, accuracy, objectivity and coverage. The review will also analyze the tables and figures before finally judging the article's accessibility and credibility. Overall it will determine if the article was well written, clear and relevant.

\section{Account Summary:}

The aim of the study: it was stated was utilizing resource-based view to examine structural factors affecting the total amount of malpractice claims costs by hospitals in Florida. It was noted in the article that malpractice is a significant concern in the provision of health care and can be an important performance measure for health care management. Medical malpractice claims, it was observed, are not only illustrative of diminished quality since by definition malpractice is a failure to meet accepted standards of professional care, but are associated with reduced access to care and increased costs in the provision of health care. Widely accepted model for assessing healthcare quality as proposed by Avedis Donabedian which is based on three distinct domains: structure, process and outcomes were looked at and each domain defined in the article. The article is of the view that in selecting consequential dimensions of quality of care, it is essential to include aspects of care significant to patients, providers and those responsible for the management of health care organizations and that the examination of outcome meets this tripartite obligation. The article provides that within the domains of structure, process and outcome, both structure and process are highly dependent on the resources of the hospital providing healthcare services. Hospitals, it was noted, are organizations whose primary purpose is to provide adequate structural and procedural components to deliver healthcare services that improve health. The article provides that resource-based view theory may offer insights into some degree of the variations in 
South American Journal of Public Health

Special Edition May 2016

malpractice claims cost performance of the subject hospitals by proposing that managers make strategic decisions about the mix of resources acquired and maintained to generate competitive advantage, and postulates that this competitive advantage may explain variations in performance.

\section{Review of Literature: Not okay yet (250 instead of 300-350)}

The article did a thorough job of identifying in literature what malpractice is, the different dimensions of medical malpractice and the attendant consequences on health performance; which it likened to costs. It went ahead to look at healthcare quality as an assessment of malpractice and the influences it has on outcomes as a competitive advantage. The literature reviewed articles within the purview of the subject area and demonstrated an appropriate depth and breadth of reading experience. The literatures reviewed were constructive, logical and succinctly presented. For instance, it first started by examining what health care quality and patient safety is and did acknowledge that assessment of quality is on the basis of observation of health performance of health care providers on established quality indicators. It adeptly expanded the scope of quality of care to include additional dimensions of effectiveness, safety, timeliness and patient centeredness. It then attempted to tie issues of quality of care to medical malpractice and went on to surmise that given the issues of standards of quality and costs associated with the provision of health care, managerial decisions relating to structure and/process in line with organizational outcomes may provide significant insights that serves to underscore the importance of looking at medical malpractice as a managerial concern. Overall, it made good use of previous studies to highlight and define the problem, at the same time, presenting his thoughts. The use of the in-text citations was well thought out and made reading a pleasure. The article was well written, grammatically correct, concise and well organized.

\section{Article Structure:}

The article was introduced with an abstract; which provided a succinct overview of the research and included information regarding the purpose of the study, method, and the main findings developed by the article. The sample size and selection, conclusions and recommendations were however, visibly absent from the abstract. This was followed by an Introduction; were the literatures of previous works relating to the topic under discuss was treated. There were many paragraphs in the body and the length was moderate with the information contained in them easy to access. The terminologies used in the article were in line with the subject under focus and the manner of writing was simple and unambiguous and that made the article easy to read and understand with minimal difficulty. The article had in addition to abstract and introduction, which is the norm, a background and theoretical perspective which provided the theoretical framework developed and adopted by the article. It highlighted the rationale behind the study and used themes from the literature that are conceptually mapped to set boundaries for the research. The framework also identified the various concepts being studied and the relationship between those concepts to the purpose of the study. The result was the formulation of four hypotheses which were clearly stated and congruent with the data presented in the literature review. Methodology and Data, was next. Here the article stated that cross-sectional data was used to demonstrate association. Identification of data sources means of measurement as well identification of indicator used in assessment was done here. The reasons for the singularity of the data type used were offered with respect to the hospitals selected for this study. In all, it was understood from the methodology and data that the study was a quasi-experimental one. The Results followed through with the presentations of its findings in tables which lend credence to the study being a correlation type of study as it used inferential statistics to arrive at its findings. Limitations and Suggestions for Future Research as well as Discussion and Practitioner Implications was the other headings found following the result. 


\section{Authority:}

The journal of Academy of Health Care Management where the article "Influences of Hospital Structures on Medical Malpractice Claims Costs" was published is peer-refereed journal which resonates well with researcher and academicians. The authors, I earlier stated, had no background information given about them as to their qualifications, position or discipline in their respective universities. Owing to such negligence, it is quite difficult to properly assess their capacity to conduct a research of this nature. However, it is believed that a research study should be evaluated on its own merits and not assumed to be valid and reliable simply based on the authors' qualifications. The only thing that can be safely assumed is that since the research was conducted in the state of Florida where the authors of the article is again assumed to be teaching or lecturing; it is believed that they conducted this research themselves.

\section{Currency:}

The article was published in the year 2011. The month of the year was however absent. The research it describes was recent and the in-text citations used in the body of the article were fairly up-to-date as at the time (ranging from 1966 to 2006). The most of the recent articles used was 2006 which is about 5 years old from the time the research study was published and that is understandable in that research in this area appear to be few and far inbetween. Nonetheless, they were all relevant and fit for the research work carried out in the article.

\section{Relevance:}

The article was published in a research journal for academic purposes. The journal is a double blind, peer refereed journal which publishes theoretical, empirical and applied manuscripts in health care. The mission of the journal is to expand the boundaries of the literature by supporting the exchange of ideas and insights which further the understanding of the health care field. In other words, it has high credibility in an academic context as it was written to inform researchers and health managers rather than to entertain or advertise. It would be relevant to researchers, healthcare professionals, other allied healthcare professionals, hospital management staff and students but particularly any person interested in healthcare quality, patient safety and medical malpractice claims costs; including how they relate with each other.

\section{Objectivity:}

The way and manner the research work was conducted right from the literature review of similar studies through to the discussion and practitioner implications showed a clear thought pattern. The expressions in the article were clear and concise. Given the subjective nature of the research, a quasi-experimental design method was adopted by the article to address the purpose for which the research was carried out. Due to the nature of the experiment, the bias element inherent in the experiment were not introduced by the authors as they did acknowledge in the limitations that the all the firms selected had "closed" malpractice claims. Thus they did not know if their result would apply to hospitals with "open" claims or hospitals with no claims whatsoever. They went ahead to indicate that all the data used consisted primarily of administrative data and the omission of clinical data was acknowledged to be a potential concern which may reduce the predictive potential of the model.

\section{Stability:}

The article was published in a research journal which is a double blind, peer refereed journal which publishes theoretical, empirical and applied manuscripts in health care. Therefore, being a research journal is as stable as resource it sought to expand the boundaries of literature by supporting the exchange of ideas and insights which further the understanding of the health care field. 
South American Journal of Public Health

Special Edition May 2016

\section{Analysis of graphs/Images/Tables:}

There were no graphs or images in the article. However, there were two (2) tables holding the findings of the article in the results section. They were both properly labeled and consist of columns and rows which are well titled. The information contained in them was well illustrated and fit very well within the space provided for them.

\section{Recent Advances Related to the Topic:}

It appears there are no recent advances related to this topic. Most of the other works done in this area are quite older than the one I just reviewed. In other words, this is the most recent work in this area.

\section{Conclusion: Not okay yet (200-250)}

This review has both summarized and critically reviewed Young and Williams article 'Influences of Hospitals Structure on Medical Malpractice Claim Costs' published in the Academy of Health Care Management Journal. The content, structure, strengths and limitations of the article were analyzed and critiqued. The article has contributed to the literature in terms of its valuable critique of current research study on medical malpractice claims costs and the role of health managers; the essence of health practitioners on issues concerning outcomes as well as competitive advantage. Wikipedia has it that medical malpractice is professional negligence by act or omission by a health care provider in which the treatment provided falls below the accepted standard of practice in the medical community and causes injury or death to the patient, with most cases involving medical error. This view is echoed in the article and raises the dire consequences it could have on access to health care and the implications on cost of provision of healthcare. For instance, a study notes that about 1.14 million patient-safety incidents occurred among the 37 million hospitalizations in the Medicare population over the years 2000-2002. Hospital costs associated with such medical errors were estimated at \$324 million in October 2008 alone (Medical Malpractice, Wikipedia).

\section{References:}

[1.] Agency for Healthcare Research and Quality. (2004). 2004 National Healthcare Quality Report (No. AHRQ Publication No. 05-0013). Rockville, MD: Agency for Healthcare Research and Quality; U.S. Department of Health and Human Services.

[2.] Allison, J., Kiefe, C., Weissman, N., Person, S., Rousculp, M., Canto, J., et al. (2000).Relationship of hospital teaching status with quality of care and mortality for Medicare patients with acute MI. JAMA, 284(10), 1256.

[3.] American Hospital Association. (2006). Chartbook 2006 Available from http://www.aha.org/aha_app/trendwatch/archive.jsp

[4.] Anderson, G., Hussey, P., Frogner, B., \& Waters, H. (2005).Health spending in the United States and the rest of the industrialized world. Health Affairs, 24(4), 903.

[5.] Barney, J., Wright, M., \& Ketchen, D. (2001). The resource-based view of the firm: Ten years after 1991. Journal of Management, 27(6), 625-642.

[6.] Barney, J. B. (1991). Firm resources and sustainable competitive advantage. Journal of Management, 17(1), 99-120.

[7.] Berwick, D. M., Calkins, D. R., McCannon, C. J., \& Hackbarth, A. D. (2006). The 100000 Lives Campaign: Setting a Goal and a Deadline for Improving Health Care Quality. JAMA, 295(3), 324-327.

[8.] Congressional Budget Office.(2006). Medical Malpractice Tort Limits and Health Care Spending. Retrieved from http://www.cbo.gov/ftpdocs/71xx/doc7174/04-28-MedicalMalpractice.pdf.

[9.] Congressional Budget Office. (2009). CBO Correspondence to Senator Orrin G. Hatch; analysis of the effects of proposals to limit costs related to medical malpractice. Retrieved 02/26/2010, 2010, from https:/www.cbo.gov/ftpdocs/106xx/doc10641/10-09-Tort_Reform.pdf

[10.] Danzon, P. M. (1994). Tort Reform: The Case of Medical Malpractice. Oxford Review of Economic Policy, 10(1),84. 
[11.] Davis, J. H., Schoorman, F. D., \& Donaldson, L. (1997).Toward a Stewardship Theory of Management. Academy of Management Review, 22(1), 20-47.

[12.] Dlugacz, Y. (2006). Measuring Health Care: Using Quality Data for Operational, Financial, and Clinical Improvement: Jossey-bass

[13.] Donabedian, A. (1966). Evaluating the Quality of Medical Care. Milbank Memorial Fund Quarterly(44), 166-203.

[14.] Donabedian, A. (1988). Quality and Cost: Choices and Responsibility. Inquiry, 25(1), 90-99.

[15.] Fahy, J., \& Smithee, A. (1999). Strategic Marketing and the Resource Based View of the Firm. Academy of Marketing Science Review(10), 1-19.

[16.] Hair, J., Anderson, R., Tatham, R., \& Black, W. (1998).Multivariate analysis. Englewood: Prentice Hall International.

[17.] Hansen, G. S., \& Wernerfelt, B. (1989). Determinants of Firm Performance: The Relative Importance of Economic and Organizational Factors. Strategic Management Journal, 10(5), 399.

[18.] Health Grades.(2004). Patient Safety in American Hospitals. Lakewood, CO.

[19.] Hitt, M. A., Bierman, L., Shimizu, K., \& Kochhar, K. (2001). Direct and moderating effects of human capital on strategy and performance in professional service firms: A resource-based perspective. Academy of Management Journal, 44, 13-28.

[20.] Hoopes, D., Madsen, T., \& Walker, G. (2003). Guest editors' introduction to the special issue: why is there are source-based view? Toward a theory of competitive heterogeneity. Strategic Management Journal, 24(10), 889-902.

[21.] Hyman, D. A., \& Silver, C. M. (2004). The Poor State of Health Care Quality in the U.S.: Is Malpractice Liability Part of the Problem or Part of the Solution? Unpublished manuscript 